\title{
Educating doctors in smoking cessation
}

4

- As part of the spectrum of endeavour concerned with - tobacco control, the activities of health care professionals, especially doctors (and particularly General Practitioners (GPs)), are widely acknowledged as being important. ${ }^{1,2,3}$ These activities include doctors' own smoking behaviour, public health and political activism, and, especially through personal contact, helping established smokers to quit. The fact that in many countries doctors have led the way in avoiding or stopping smoking has enhanced their potential for making a major contribution to tobacco control and reinforced their exemplary role ${ }^{4}$; in this respect at least, doctors provide good role models and can be said to "practise what they preach". In 1988, a survey of a random sample of 5000 British GPs revealed that less than $5 \%$ were cigarette smokers. ${ }^{5}$

Furthermore, the efficacy of minimal medical intervention in assisting smoking cessation in patients consulting doctors has been established by rigorous scientific research $^{6,7}$ and the cost-effectiveness of this has been shown ${ }^{8}$ to compare very favourably with other preventive actions. As a medical student 40 years ago I, along with many of my contemporaries, smoked cigarettes, ignorant of their potential harm. So did the majority of my medical teachers, including the Professor of Medicine! But the situation is now very different - or is it? The paper ${ }^{9}$ by Tessier et al. in this issue completes an impressive survey of smoking prevalence amongst medical students in 42 countries; as well as ascertaining their smoking behaviour, the study also elicited their knowledge about and attitudes towards smoking. In general, smoking prevalence in medical students in each country reflects, but is below, that in the population of that country as a whole; in Northern European countries, Australia, the USA, and Japan, smoking prevalence in medical students is well below that in the population as a whole. But in all countries, knowledge about the relationship between smoking and disease is limited; in all countries too, but especially in Japan and the former USSR, this ignorance even extends to lung cancer, with less than a quarter of students in some countries regarding smoking as an important cause of this disease.

Even in those countries where we assume doctors' knowledge of the dangers of smoking can be taken for granted (and where cigarette smoking amongst doctors is now a rarity), a major problem remains the gap between having this knowledge and its translation into health care practice. In spite of the evidence that patients expect to be asked by their doctors about smoking, ${ }^{10,11}$ and that doctors claim to ask and advise about it, ${ }^{12}$ only a minority of smokers report that they have in fact been asked and advised by their doctors to stop, ${ }^{13}$ though the situation does seem to be improving. ${ }^{14}$ Given the importance of tobacco smoking as a major cause of disease and the evidence of effectiveness of smoking cessation interventions by doctors, this is disappointing. Why does smoking not receive the same "clinical" attention as, say, hypertension or hypercholesterolaemia?

This deficiency may be partly attributable to the feeling many doctors may have that they are ill-equipped with the knowledge, techniques and confidence to help with smoking cessation and to the common view that advice has little impact anyway. Another report ${ }^{15}$ in this issue, by Jones et al. of a study of the effectiveness of a training programme in smoking cessation for GPs, illustrates an attempt to remedy this problem. The study showed that a single smoking cessation workshop temporarily improved the recording of smoking status in the medical records and the offer of cessation advice to patients, but six months later the effect had faded and things were as before. In the same way that smoking cessation advice given on a single occasion and without reinforcement or follow-up, may have only a limited effect, ${ }^{6}$ so it seems that a single workshop on how to do it may not be very effective either. It has been shown, however, that training doctors in smoking cessation techniques can increase the likelihood of their advising patients to stop smoking and that the patients of doctors who have received such training are more likely to make attempts to stop smoking than those who are patients of untrained doctors. ${ }^{16}$

Educating medical students and doctors about the importance of smoking as a cause of disease is the first step in getting doctors involved in smoking cessation. As Tessier et al. show, there is considerable scope for improving knowledge about smoking amongst medical students in all countries. Knowledge about smoking as a behaviour, particularly its addictive nature, is even more limited than that of the epidemiology of smoking. When it comes to smoking cessation techniques, ignorance is still more profound, which is, perhaps, un-surprising, given the inattention which the subject receives at all levels of medical education. Furthermore, even when knowledge about smoking is substantial, there still remains the hurdle of implementation, when the demands of the patient's presenting problems and of acute medical needs generally override the intention to practise prevention. So even those doctors who are well informed about the medical consequences of tobacco smoking, about how to implement a smoking cessation strategy, and who are highly motivated to practise preventive medicine, may find their efforts constrained by the immediate expectations of the patient and the "treatment" mode of most health care systems.

What can be done about it? Much lip service is paid to prevention but in practice its implementation is patchy. Tobacco smoking is the most important preventable cause of disability and premature death in developed countries and an increasingly important one in the developing world, and the medical curriculum should reflect this. Since my medical student days, we have acquired a vast body of knowledge about smoking and disease and about smoking as an addictive behaviour. Medical interventions have also become more sophisticated, especially forms of nicotine replacement therapy. The slim volume reviewed by Dr. Tom Glynn is this issue is an example of the useful, expert material on smoking cessation which is now available and which should be widely disseminated.

Medical education, particularly at a pre-graduate level, has failed to take adequate account of the importance of smoking and urgently needs to do so. The effects of tobacco smoking and the "treatment" of smoking behaviour deserve a place in the curriculum alongside such topics as the effects of high blood pressure and the treatment of hypertension or the treatment of diabetes. The medical treatment of disease occupies a major part of the medical curriculum but drug treatment offers little in the management of cardiovascular and respiratory diseases, and surgery is a poor substitute in the management of peripheral vascular disease, compared with the benefits of smoking avoidance.

GODFREY FOWLER

Associate Editor

Oxford University,

Oxford, UK

Oxford, UK 
This year's World No-Tobacco day (31 May 1993), sponsored by the World Health Organisation, is dedicated to the theme "Health Services: Our Window to a Tobacco-Free World". - ED

1 Davis RM. Uniting physicians against smoking: the need for a coordinated national strategy. $7 A M A$ 1988; 259:2900-1.

2 Royal College of Physicians of London. Preventive medicine : a report of a working party. 1991. Royal College of Physicians, London.

3 Reid DJ, Killoran AJ, McNeill AD, Chambers JS. Choosing the more effective health promotion options for reducing a nation's smoking prevalence. Tobacco Control 1992; 1 : 185-197.

4 Adriaanse H, Van Reek J. Physicians' smoking and its exemplary effect. Scand $\mathcal{F}$ Prim Health Care 1989; 7 : 193-6.

5 Fowler G, Mant D, Fuller A, Jones L. The 'Help your patient to stop' initiative: evaluation of smoking prevalence and dissemination of WHO/UICC guidelines in UK general practice. Lancet $1989 ; 1: 1253-5$.

6 Russell MAH, Wilson C, Taylor C, Baker C. Effect of general practitioners' advice against smoking. $B M \mathcal{F} 1979 ; 2: 231-5$.

7 Kottke TE, Battista RN, DeFriese GH, Brekke ML. Attributes of successful smoking interventions in medical practice: a meta-analysis of 39 controlled trials. fAMA 1988; 259: 2883-9.
8 Cummings SR, Rubin SM, Oster G. The cost-effectiveness of counselling smokers to quit. $\mathcal{F} A M A 1989 ; 261: 75-9$.

9 Tessier JF, Freour P, Nejiari C, Belougne D, Crofton J. Smoking behaviour and attitudes of medical students towards smoking in Australia, Japan, USA, Russia, and Estonia. Tobacco Control 1993; 2: 24-9

10 Slama K, Redman S, Cockburn J, Sanson-Fisher R. Community views about the role of general practitioners in disease prevention. Family Practice $1989 ; 6$ : $203-9$.

11 Owen N, Davies $M$. Smokers' preference for assistance with cessation. Preventive Medicine 1990; 19: 424-431.

12 Wechsler H, Levin S, Idelson R, Rothman M, Taylor JD. The physician's role in health promotion - a survey of primary care practitioners. $N$ Engl rol Med $1983 ; 308: 97-100$.

13 Marsh A, Matheson J. Smoking attitudes and behaviour: an enquiry carried out on behalf of the Department of Health and Social Security. HMSO, London 1983.

14 Gilpin E, Pierce J, Goodman J et al. Trends in physicians giving advice to stop smoking, United States. Tobacco Control 1992; 1: 31-5.

15 Jones CA. Response to a smoking cessation workshop by family practice resident physicians. Tobacco Control 1993; 2: 30-4.

16 Kottke TE, Brekke ML, Solberg LI, Hughes JR. A randomised trial to increase smoking intervention by physicians. $\mathscr{f} A M A 1989 ; 261: 2101-6$.
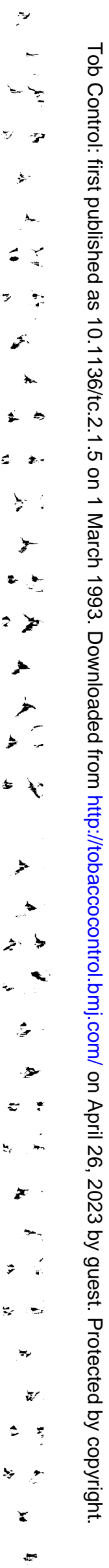

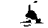

